\title{
PRUEBA PROCESAL, PRESUPUESTO DE LA TUTELA JUDICIAL EFECTIVA ${ }^{1}$
}

\author{
PROOF OF PROCEDURE, FOR EFFECTIVE JUDICIAL PROTECTION
}

\author{
JAIRO JOSÉ GUZMÁN GARCÍA \\ Universidad Centroamericana (UCA) \\ Nicaragua
}

\author{
Recibido: $27 / 03 / 2017$ \\ Aceptado: 01/09/2017
}

Resumen: Una de las concreciones del derecho humano a la tutela judicial efectiva es que toda persona, cuando reclama amparo de sus intereses jurídicamente relevantes, debe obtener una resolución apegada, de la mejor manera posible, a la verdad de aquellos hechos en los que se apoyan sus peticiones. Ello justifica que el desarrollo de este trabajo aborde varios temas tocantes a la prueba. Iniciamos con la noción de prueba y su relación con el proceso; en seguida, dirigimos la atención hacia la tipificación de los principios involucrados en la prueba, para culminar con el tratamiento del objeto y la función a que se endereza el estudiado instituto jurídico. En este último punto, se realiza una exposición sobre la relación entre prueba y verdad de los hechos.

Palabras clave: prueba judicial, principios de la prueba, hechos, verdad judicial.

Abstract: One of the precisions of the human right for an effective judicial protection is that
any person who claims protection, obtains a resolution that adheres in the best possible way to the
truth of the facts on which the addressed petitions to the court are based. In the present document,
several issues related to evidence are discussed in order to provide a general overview of the legal
implications. As a first step, the notion of evidence and its relation to the process is debated; after
that we turn our attention towards the typification of the principles involved in the evidence, to
culminate with the treatment of the object and the function to which the studied legal institute is
directed. In this last point, a discussion is made on the relation between evidence and truth of facts.

Keywords: judicial evidence, principles of the evidence, acts, judicial truth.

SUMARIO: INTRODUCCIÓN 1. PROCESO JUDICIAL Y NOCIÓN DE LA PRUEBA QUE EN ÉL SE PRODUCE. 2. TIPOLOGÍA DEL DERECHO DE LAS PARTES A UTILIZAR LOS MEDIOS DE PRUEBA. 2.1. Una aproximación desde la teoría general del Derecho. 3. PRINCIPIOS PROCESALES DE LA PRUEBA JUDICIAL. 3.1. Principio de oportunidad. 3.2. Principio dispositivo. 3.3. Principio de aportación de parte. 4. OBJETO Y FUNCIÓN DE LA PRUEBA JUDICIAL. 4.1. Los hechos: elementos fundamentales en el tema de la prueba. 4.2. El objeto de la prueba. 4.3. La función de la prueba. 4.3.1. La verdad como elemento de descubrimiento y de justificación.

1 Este trabajo fue realizado por el autor gracias a la concesión de una estancia de investigación de dos meses en el Departamento de Ciencias Jurídicas de la Universidad de Alcalá, a través del Programa Giner de los Ríos de Profesores investigadores invitados, de enero a marzo de 2017. 


\section{INTRODUCCIÓN}

En los tiempos que corren, el fenómeno de la mimetización de modelos jurídicos a través de los ordenamientos nacionales constituye parte de la globalización característica de las sociedades actuales, y como manifestación de ello se presenta la tutela cada vez mayor de valores y principios considerados de superior condición a efectos del respeto irrestricto de la persona humana.

Uno de esos valores se halla cifrado en la noción del derecho a obtener tutela judicial efectiva, contenida de forma general en buena parte de los textos constitucionales, al menos de los ordenamientos occidentales, mismo que se expresa y concreta por medio de otros principios procesales y que en el caso del proceso civil tiene sus puntuales especificidades. Es el caso de los ordenamientos jurídicos español y nicaragüense, los cuales también de forma similar cuentan con legislaciones procesales en el ámbito civil, más o menos recientes que deben responder a la realización de la mentada tutela judicial efectiva, que siendo un concepto ampliamente estudiado en la doctrina, conviene que en esta parte del trabajo dejemos tan sólo esquemáticamente expuesto.

Efectivamente, el derecho subjetivo que puede considerarse clave para la exposición del resto de temas de esta investigación, mismo que se halla contenido en los textos constitucionales español y nicaragüense, se puede comprender de forma concreta a través de lo que ha expresado el Tribunal Constitucional español. Específicamente $^{2}$ dicha jurisprudencia ha acuñado los elementos estructurales de tal derecho: el justiciable es titular de la facultad de exigir y obtener de cualquier órgano judicial una resolución apegada a parámetros de congruencia y justificación -motivaciónestructurada lógicamente a partir del Derecho.

De tal caracterización, que podría considerarse conceptual, el T.C español hace derivar algunas puntualizaciones: la motivación se concreta en que la sentencia exprese cuáles son los criterios jurídicos que han sido considerados como aplicables y fundamentales para la decisión -v. STC 58/1997 de 18 de marzo-. Tales criterios de motivación deben estar contenidos en el ordenamiento jurídico y han de aplicarse como consecuencia de una labor exegética racional que indique la pertinencia de los mismos respecto a la realidad social que se está valorando por medio de los hechos expuestos por las partes, y por tanto no es fruto de una arbitraria actuación del judicial-V STC 25/2000, de 31 de enero-.

Por la antes señalada similitud, el presente trabajo procura destacar de forma puntual la manera en que el citado derecho constitucionalizado se manifiesta y hace posible a través del mecanismo de la prueba judicial y del correspondiente derecho a hacer uso de ella, centrando en primer lugar la atención en consideraciones generales sobre la relación de este derecho con los principios procesales propios de la materia. Posteriormente, se presenta la discusión sobre el objeto de la prueba como presupuesto formal y a la vez material de la motivación de las resoluciones judiciales.

Así, procuramos traer a estas páginas la exposición de temas específicamente elegidos, respecto de los cuales la doctrina y jurisprudencia española pueden brindar valiosos

\footnotetext{
2 Puede verse la sentencia 50/2014, de 7 de abril.
} 
aportes a la discusión jurídica en el ámbito nicaragüense, y a la inversa, al estudioso o investigador español, podría brindarle información útil sobre la manera en que se exponen y tratan en el ordenamiento de Nicaragua los puntos abordados en la investigación.

\section{PROCESO JUDICIAL Y NOCIÓN DE LA PRUEBA QUE EN ÉL SE PRODUCE}

En la experiencia social se ha mostrado constante la necesidad de existencia de mecanismos que respondan a la solución de controversias de intereses que se plantean entre los sujetos de Derecho, y para nadie constituye una sorpresa que el proceso judicial, antaño como hogaño ha sido utilizado como una fórmula de heterocomposición del conflicto.

Así, se comprende que la doctrina exponga que el proceso constituye una serie de actos que tienen directriz jurídica a través de la ley, y por tanto, es el medio idóneo por el cual, la autoridad judicial dirime de forma imparcial los conflictos de intereses que tienen relevancia jurídica ${ }^{3}$, y por tanto elemento esencial de la jurisdicción ${ }^{4}$

Así, es lógico que en el Proceso se produzca, como ha dicho la doctrina, una tensión dialéctica entre pretensión y resistencia ${ }^{5}$, entre afirmación y contradicción -que puede ser total o parcial- respecto a los hechos expuestos -en principio- por medio de la demanda y la correspondiente contestación.

En las legislaciones procesales, destaca como elemento integrante del proceso, la prueba, parte de una secuencia de actuaciones que las partes deben realizar ante el órgano judicial. El proceso inicia con la demanda, en la cual se encuentran fijados los hechos constitutivos del interés que se pretende tutelar por parte del demandante -pretensión-, frente a la cual el demandado deducirá también en su contestación circunstancias -hechos- con las que pretenderá, por lo general, desvirtuar lo solicitado en la demanda -resistencia-. Cuestión que explica MONTERO AROCA 6 , en el sentido de que mientras el objeto del proceso se encuentra determinado exclusivamente por el actor a través de la pretensión, la resistencia del demandado coadyuva a la determinación de algo distinto de ese objeto del proceso: el objeto del debate.

El citado autor ${ }^{7}$ acota que la pretensión presenta elementos subjetivos y objetivos, en estos últimos, se identifica aquello que se pide, es decir, el petitum y la razón o causa por la cual se pide o causa petendi. El petitum representa el verdadero objeto

E. J. COUTURE, Fundamentos del Derecho Procesal Civil, Buenos Aires, 1958, p. 10. J. GARBERÍ LLOBREGAT, G. BUITRÓN RAMÍREZ, La prueba Civil. Doctrina, jurisprudencia y formularios sobre prueba y medios de prueba en la nueva Ley de Enjuiciamiento Civil, Valencia, 2004, p. 25.

4 El proceso penal es, como el civil, el laboral o el contencioso-administrativo, un instrumento esencial de la jurisdicción : T. ARMENTA DEU, Lecciones de Derecho Procesal Penal, Madrid, 2016, p. 31.

J. L. SEOANE SPIEGELBERG, La prueba en la Ley de enjuiciamiento civil 1/2000, disposiciones generales y presunciones, Pamplona, 2002, p. 17.

6 J. MONTERO AROCA, La Prueba en el proceso civil, Pamplona, 2005, p. 29.

J. MONTERO AROCA, La Prueba..., cit., p. 30. 
del proceso civil pues por su medio, el demandante acude voluntariamente al órgano jurisdiccional a "pedir" que se declare como propio o a su favor algún contenido o expresión de derechos subjetivos. En cambio, Causa petendi es el o los hechos acontecidos a los cuales se ha reconocido virtualidad de producir determinados efectos jurídicos ${ }^{8}$. Así, por ejemplo, en una acción judicial de desahucio por terminación del contrato a propósito de un arrendamiento de finca, el petitum consistiría normalmente, en la recuperación física del inmueble por parte del arrendador, titular de un derecho de dominio o de cualquier otro ius in re aliena con suficiente entidad para dar en arriendo el bien, y, causa petendi, la llegada del tiempo fijado contractual o legislativamente para la pérdida de efectos jurídicos de dicha relación.

Dentro del desarrollo del proceso, la respuesta que el demandado plantea frente a la demanda revelará, por lo general, la intención de ser afectado lo menos posible en sus intereses, pidiendo no ser condenado y por ello traerá al proceso hechos que desvirtúen o introduzcan modificaciones respecto a las afirmaciones y peticiones del demandante, aunque tales hechos no pueden alterar la determinación del objeto del proceso planteado efectivamente a través de la pretensión?.

Se plantea así, una dialéctica contraposición de intereses en torno a una realidad social determinada en torno a la cual existen afirmaciones y contra afirmaciones relativas a hechos ${ }^{10}$, las cuales deben ser aceptadas o rechazadas por el juez en la resolución, como parte de la labor declarativa de la existencia de un derecho subjetivo que asiste a una de las partes.

Aparece así la necesidad de reconocer, en principio, que en el proceso, la prueba versa sobre las afirmaciones que de los hechos las partes exponen por medio de sus alegaciones, y que ello guarda un ineludible punto de conexión explicativa con la noción epistemológica del Derecho, que debe ser considerada como una ciencia del espíritu ${ }^{11}$, propiamente una de tipo argumentativo ${ }^{12}$.

En fin, la prueba debe tenerse como la actividad que hace posible que las partes practicando los distintos medios de prueba, consigan acreditar los hechos que con-

8 J. MONTERO AROCA, La Prueba..., cit., p. 30.

9 J. MONTERO AROCA, La Prueba..., cit., p. 31.

10 Como bien reconocen GARBERÍ LLOBREGAT, BUITRÓN RAMÍREZ, la prueba civil..., cit., p. 25 s, de las alegaciones hechas por las partes, solamente adquieren auténtica relevancia, las relativas a los hechos o argumentos fácticos, pues son elementos identificadores e individualizadores de las pretensiones y resistencias que son en definitiva, límite y contenido de los poderes de decisión del órgano judicial. Podría sostenerse que de todo lo que integra tanto la pretensión como la resistencia, lo más importante son los hechos puesto que son elementos absolutamente necesarios para el que el juez ejercite la potestad jurisdiccional.

${ }^{11}$ I, FLORES MENDOZA, "El porvenir de la ciencia jurídica. Reflexión sobre la ciencia y el Derecho", en, Instituto de Investigaciones jurídicas de la Universidad Autónoma de México, La ciencia del Derecho durante el siglo XX, México D. F, 2004, pp.1006 a 1027. Especialmente en cuanto a la exposición sobre la consecuencia del pluralismo epistemológico debe tener en la discusión sobre la cientificidad del Derecho. -Idem, pp.1024 a 1026-.

12 C. VILLABELLA ARMENGOL, La investigación y comunicación científica en la ciencia jurídicas, Managua, 2009, p. 47. 
forman y en que fundamentan sus posiciones dentro del proceso ${ }^{13}$, y se debe entender como un derecho subjetivo correspondiente a las partes.

La prueba pues, determina el material intelectual para que el juez adopte y razone la decisión en torno a la controversia planteada, y sobre el mismo se construirá también la sustancia argumental de la motivación a que se encuentra obligado constitucionalmente ${ }^{14}$. Esta es la importancia que la prueba tiene respecto al proceso en pos de la obtención de tutela judicial efectiva.

Como derecho subjetivo que es, la utilización de la prueba por las partes del proceso debe ser definido desde el análisis del tipo de derecho a que corresponde, lo cual se realiza a continuación.

\section{TIPOLOGÍA DEL DERECHO DE LAS PARTES A UTILIZAR LOS MEDIOS DE PRUEBA}

Desde una perspectiva general, la estudiada facultad de las partes procesales de utilización de los medios de prueba se puede circunscribir dentro de la calificación de "derecho fundamental" 15 .

Desde la experiencia jurisprudencial, es tenida como componente de un conjunto de derechos subjetivos que corresponden a cada individuo, no solamente en cuanto derechos de los ciudadanos, sino también en cuanto garantizan una suerte de status o condición jurídica o la libertad en un ámbito de la existencia al tiempo que se deben tener como elementos esenciales de un orden objetivo de la comunidad nacional para el logro de una convivencia lo más justa y pacífica posible ${ }^{16}$.

Noción que encaja bien con lo expresado en sede doctrinal ${ }^{17}$ que los considera como facultades reconocidas por un ordenamiento jurídico a todas las personas $-\mathrm{O}$

13 GARBERÍ LLOBREGAT, BUITRÓN RAMÍREZ, la prueba civil..., p. 28.

14 Art. 24.2 CE. Art. 34.8 Cn. de Nicaragua.

15 Que como recuerda el Tribunal Constitucional español, en sentencia 21/1981 de 15 de junio, F. J 10 -publicada en el BOE de 15 de julio de 1981-, son aquellos que responden a un sistema de valores y de principios de alcance universal que subyacen a la Declaración Universal de los Derechos Humanos de 1948, y a los diversos convenios internacionales ratificados por el Estado español. Noción que perfectamente se puede aplicar al Derecho nicaragüense, especialmente a partir del contenido del artículo $46 \mathrm{Cn}$ que reconoce la plena vigencia en el ordenamiento jurídico de los instrumentos internacionales de derechos humanos ahí consignados, dentro de los cuales destaca la Declaración Universal de los Derechos Humanos de 1948. Y que, en el ámbito doctrinal, en similar sentido se entiende como: fundamento del orden político de una sociedad. Expresan los espacios de dignidad de la persona humana, considerados indispensables para la convivencia democrática .": M. D. OLLER SALA, "El derecho a la utilización de los medios de prueba como factor de dinamización del derecho probatorio", en, X. ABEL LUCH, J. PICÓ I JUNOY, M. RICHARD GONZÁLEZ, (dir.), La prueba judicial. Desafíos en las jurisdicciones civil, penal, laboral y contencioso administrativa, Madrid, 2011, pp. 293, 304. En el mismo sentido, J. PICÓ I JUNOY, El derecho a la prueba en el proceso civil, Barcelona, 1996, p. 20 (nota 19).

16 V. F.J 5 de la STC 21/1981.

17 L. FERRAJOLI, Los fundamentos de los derechos fundamentales. Debate con Luca Baccelli; Michelangelo Bovero; Riccardo Guastini; Mario Jori; Anna Pintore; Ermanno Vitale; Danilo Zolo, Madrid, 2009, p.19. 
en su caso, sólo a todos los ciudadanos- por el mero hecho de serlo, derechos inherentes a la condición de persona acorde con la concepción que de ello se halle plasmado en dicho ordenamiento ${ }^{18}$.

Además, entendido como derecho fundamental, el tratado concepto, cumple como todos los que entran en dicha calificación, un doble propósito ${ }^{19}$ : legitimación y protección; entendiendo como legitimación, la función por la cual los derechos fundamentales son criterios de calificación de lo justo o injusto que puede resultar una determinada actuación ya sea pública o privada, como protección se entiende que constituyen instrumentos de protección frente a las posibles arbitrariedades del poder público en todos sus órdenes.

Específicamente, tal naturaleza del derecho a utilizar los medios de prueba se puede configurar en el ordenamiento constitucional nicaragüense como producto del análisis y la conjunción de nociones derivadas de varios artículos del texto constitucional.

El artículo 5 determina que dentro de los principios constitutivos de la nación está el respeto a la dignidad de la persona humana, acogiendo además ideales socialistas que procuran la construcción de una sociedad cada vez más justa y equitativa, ello armoniza con los objetivos que se plantean en el artículo 34 al determinar -en su numeral 1- que los ciudadanos tienen el derecho al debido proceso y a la tutela judicial efectiva, y en consecuencia, se han de considerar "inocentes" en tanto, por medio de la correspondiente "prueba" se llegue a la demostración de lo contrario. De forma más concreta el derecho a utilizar los medios de prueba se contiene en el numeral 4 del citado artículo $34 \mathrm{Cn}$. como mecanismo de defensa en cualquier tipo de proceso, determinando que toda persona ha de disponer de tiempo y de medios para realizar la defensa de su posición jurídica.

Lo antes dicho se completa con el contenido normativo del artículo $46 \mathrm{Cn}$., pues determina que toda persona dentro del territorio del Estado es titular de los derechos inherentes a la persona humana y sujeto de los derechos humanos, especialmente de aquellos que se consignan en los instrumentos internacionales que en su texto se mencionan. De entre ellos, vale destacar, además de la Declaración Universal de los Derechos Humanos de 1948, algunos, como la Convención Americana de los derechos humanos -o Pacto de San José de 1969-, artículo 8 literal "a”, que determina la garantía judicial consistente en que mientras dure el proceso todas las personas se hallan facultadas, en plena igualdad, a determinadas garantías consideradas como "mínimas", y entre las cuales dispone "Concesión al inculpado de tiempo y de los medios adecuados para la preparación de su defensa ...”; también es destacable el artículo 14 del Pacto internacional de Derechos civiles y políticos de la ONU,

18 Téngase en cuenta que en este punto pareciera confundirse la noción de derechos fundamentales con los derechos de la personalidad, no obstante, se ha considerado que a pesar de que todos los derechos de la personalidad también son derechos fundamentales no todos los derechos fundamentales pueden ser considerados como de la personalidad. Para esta distinción puede verse la exposición que realiza J. E BUSTOS PUECHE, Manual sobre bienes y derechos de la personalidad, Madrid, 2008, p. 38 ss.

19 L. M. DÍEZ PICAZO GIMÉNEZ, Sistema de derechos fundamentales, Pamplona, 2013, p. 19. 
adoptado y abierto a la firma, ratificación y adhesión por la Asamblea General en resolución 2200 A, de 16 de diciembre de 1966, entrada en vigor a partir del 23 de marzo de 1976, que al efecto establece: ...1. Todas las personas son iguales ante los tribunales y cortes de justicia. Toda persona tendrá derecho a ser oída públicamente y con las debidas garantías por un tribunal competente, independiente e imparcial, establecido por la ley, en la substanciación de cualquier acusación de carácter penal formulada contra ella o para la determinación de sus derechos u obligaciones de carácter civil....3. Durante el proceso, toda persona acusada de un delito tendrá derecho, en plena igualdad, a las siguientes garantías mínimas:...b) A disponer del tiempo y de los medios adecuados para la preparación de su defensa y a comunicarse con un defensor de su elección;...e) A interrogar o hacer interrogar a los testigos de cargo y a obtener la comparecencia de los testigos de descargo y que éstos sean interrogados en las mismas condiciones que los testigos de cargo...".

Las consideraciones anteriores, hechas desde la experiencia eminentemente legislativa, también encuentran reflejo en las exposiciones doctrinales propias de la Teoría General del Derecho, como se verá a continuación.

\subsection{Una aproximación del derecho a utilizar la prueba desde la teoría ge- neral del Derecho}

A partir de las ideas expuestas por FERRAJOLI, el estudiado derecho a utilizar los medios de prueba, también cumple las condiciones para ser considerado un derecho fundamental.

El encuadre teórico de los derechos fundamentales parte, como no podía ser de otra manera, de su concepción y de los elementos que los caracterizan, singularizándolos de otras tipologías de derecho.

Así, el citado autor plantea que los derechos fundamentales tienen como puntos fundamentales ser, "derechos subjetivos" que corresponden "universalmente" a todo tipo de personas -todos los seres humanos que por ello se encuentran reconocidos con el estatus de "persona"-, facultades dispuestas en cada particular ordenamiento jurídico, y a renglón seguido, expone también que las características esenciales de este tipo de derechos subjetivos son tres, a saber ${ }^{20}$ :

a) Forma universal de su imputación

b) Su estatuto de reglas generales y abstractas

c) Su carácter indisponible e inalienable

Por derecho subjetivo se entiende, según el autor cuya exposición seguimos en este apartado, cualquier expectativa positiva -de prestaciones-o negativa -de no sufrir lesiones- de la cual los ordenamientos jurídicos hacen titular a los sujetos de Derecho por medio de una norma ${ }^{21}$. La utilización de los medios de prueba en los procesos judiciales constituye un derecho subjetivo porque es una expectativa que en

20 L. FERRAJOLI, Los fundamentos..., cit., p. 19, 291 s.

21 L. FERRAJOLI, Los fundamentos..., cit., p. 19, $291 \mathrm{~s}$. 
dependencia de la posición procesal que se ocupe puede ser positiva o negativa en razón de que constituye, en el proceso civil, una actividad realizada a fin de acreditar la fehaciencia o verosimilitud de las razones expuestas ante la autoridad judicial.

Es una facultad en toda regla, la cual se reconoce tanto en el ordenamiento español como en el nicaragüense dentro de las disposiciones del texto constitucional -arts. 24.2 CE.; 34.4 Cn.--, de forma universal en todo supuesto procesal, a toda persona nacional o extranjera que se encuentre en el ámbito territorial de validez de su Derecho, a los cuales también se reconoce en ambos ordenamientos, como titulares de la facultad tantas veces mencionada ${ }^{22}$, cuestión que igualmente implica considerar que el carácter de tales normas -que constituyen su estatuto-, determina la categoría más general y abstracta dentro del ordenamiento. Y por lo que hace a la caracterización como indisponibles e inalienables, se puede explicar que el derecho a la prueba también, incumbe de igual forma y medida a todos sus titulares ${ }^{23}$ siendo además su práctica un deber del Estado, por medio de los tribunales que deben motivar sus sentencias ${ }^{24}$ y ello requiere, entre otros extremos, atender a lo probado en el proceso ${ }^{25}$.

Así pues, el derecho a la utilización de los medios de prueba constituye, tanto desde la perspectiva eminentemente legislativa como doctrinal, un derecho fundamental.

La trascendencia práctica de la facultad de utilizar los medios de prueba como elemento esencial para la realización de tutela judicial efectiva a la luz de la doctrina, la legislación y la teoría general del Derecho, permite dirigir nuestra atención a los

22 Que es un derecho subjetivo universal tanto en el aspecto subjetivo como objetivo, es decir aplicable en todo supuesto y a cualquier sujeto que se encuentran en el territorio sobre el que se ejerce soberanía. Esta explicación encuentra encaje en la interpretación de algunos textos constitucionales. En cuanto al Derecho español, se puede mencionar el artículo 9.3 de la Constitución, que establece el principio de seguridad jurídica, que sirve como fundamento a que el artículo 13, reconozca a los extranjeros como sujetos de libertades públicas que se garantizan en el Título al que pertenece el artículo 24, por el cual se indica que toda persona en España tiene derecho a la tutela judicial efectiva, y que uno de las manifestaciones por la que tal se realiza, es el derecho a la utilización de los medios de prueba. En igual sentido, se descubre que, en el ordenamiento constitucional de Nicaragua, el principio de seguridad jurídica -art. 25.2- da pie a los principio del debido proceso y tutela judicial efectiva -contenidos en el artículo 34-, derivándose de ellos el derecho a la defensa a través de disponer de tiempo y medios adecuados para su defensa -numeral 4 del art. 34-, lo cual es universalmente reconocido como facultades propias de todo sujeto de Derecho, sea nacional o extranjero -art. $27,2^{\circ}$ párrafo: los extranjeros tienen los mismos deberes y derechos que los nicaragüenses-.

23 L. FERRAJOLI, Los fundamentos..., cit., p. 292.

24 V. Art. 34.8 Cn. de Nicaragua: A que se dicte sentencia motivada, razonada y fundada en Derecho dentro de los términos legales. Y, art. 120.3 CE.

25 "Parece claro que el control social de la actividad jurisdiccional no debe quedar limitado al desenvolvimiento de las actuaciones procesales, sino que debe extenderse también al acto al cual el proceso se dirige: a la decisión judicial (...) El artículo 120.3 de la norma fundamental revela la preocupación del legislador constituyente por un aspecto puntual de la actividad judicial. El Juez ha de responder convenciendo, aplicando las normas legales, justificando las causas fácticas y jurídicas de su decisión; con ello se hace posible, entre otras cosas, el necesario control de las resoluciones por la vía de los recursos": F. GUTIÉRREZ-ALVIZ; V. MORENO CATENA; “Artículos 113 a 127 de la Constitución Española de 1978”, en, O. ALZAGA VILLAAMIL, F. FERNÁNDEZ SEGADO, (dirs.), Comentarios a la Constitución Española Tomo IX, Madrid, 2006, pp. 404, 405. 
principios jurídicos que informan el estudio de la prueba y lo haremos procurando analizar la temática desde una perspectiva más atenta a aspectos que quizá se ha considerado de menor calado por parte de la doctrina especializada ${ }^{26}$.

\section{PRINCIPIOS PROCESALES DE LA PRUEBA JUDICIAL}

Como se deduce de todo lo expresado, el tema de la prueba procesal plantea una conjugación entre realidad y supuestos jurídicos, dada la necesaria relación que existe entre vida social y ciencia del Derecho. Relación que hace posible que todo cuanto se quiera acreditar a efectos de tener mayor o menor éxito en una litis -hechos o negocios jurídicos-, deba serlo a consecuencia de la vigencia y puesta en práctica de algunos principios del ordenamiento, cuales son, en general, el principio de seguridad jurídica ${ }^{27}$ y específicamente en materia procesal, los de defensa, tutela judicial efectiva, y más precisamente los que derivados de los antes mencionados corresponden de manera formal al proceso civil, cuales son el principio de oportunidad, dispositivo y el de aportación de parte.

\subsection{Principio de oportunidad}

No obstante el uso y comprensión del principio de oportunidad que en materia penal $^{28}$ fue planteado en Europa a partir de finales de la Primera Guerra mundial como manifestación del carácter "público" de la acción penal, y por el cual se faculta al órgano estatal que ejerce la acción penal la determinación, jurídicamente regla-

26 TARUFFO, Michele, en el prólogo a, J. FERRER BELTRÁN, Prueba y verdad en el Derecho, Madrid, 2002, pp. 9, 10.: El mismo error, por otra parte está ampliamente difundido entre los juristas y en particular, entre los procesalistas. Éstos, en efecto, tienden a sobrevalorar fuertemente los aspectos teóricos del fenómeno probatorio y a sostener que los juristas deberían dedicarse exclusivamente al estudio de los aspectos jurídicos del mismo. Ambos grupos, teóricos y juristas parten de la premisa -a su vez errónea, pero ampliamente compartida- según la cual los aspectos jurídicos y teóricos del problema de la prueba pueden ser tratados independientemente, como si entre ellos no se dieran numerosas y relevantes interconexiones. () Todo esto ha tenido como consecuencia graves limitaciones y distorsiones relevantes tanto en la cultura filosófica como en la jurídica en relación con la decisión sobre los hechos.

$27 \mathrm{Al}$ respecto se ha dicho, que constituye "índice referencial de la seguridad jurídica, la búsqueda de la verdad se constituye en la finalidad a la que básicamente se orientan, procurando el acierto de las decisiones judiciales, las normas procedimentales y procesales sobre constataciones y alegaciones y prueba".: A. LUNA SERRANO, La seguridad jurídica y las verdades del Derecho, Madrid, 2015, p. 26.

28 "La incorporación del principio de oportunidad en el proceso penal es un tema que plantea bastante controversia en el ámbito en que operan los sistemas de enjuiciamiento criminal de los países con tradición continental. Pero, ¿a qué responde el citado principio de oportunidad? MORENO CATENA nos facilita la definición del mismo, atribuyéndosela a GIMENO SENDRA, como facultad, que al titular de la acción penal asiste, para disponer, bajo determinadas condiciones, de su ejercicio, con independencia de que se haya acreditado la existencia de un hecho punible contra un autor determinado...": C. VAQUERO LÓPEZ, "Principio de oportunidad y mediación. Alternativa viable y necesaria", Revista de Mediación, No 11, 2012, p. 11. 
mentada, de la oportunidad de su ejercicio, también se ha presentado en tiempos más recientes, útil en el proceso civil ${ }^{29}$ a efectos de explicar que en este ámbito, los sujetos de derecho poseen, por un lado, la facultad de determinar la o las relaciones jurídicas en las cuales se ubicarán como parte -en el caso civil, en ejercicio de la autonomía privada-; y por otro, que se hallan habilitados para decidir cuál sea la manera más adecuada para defender los intereses que de tales posiciones deriven, esto es, exigir el respeto del contenido de sus derechos ${ }^{30}$.

Tales consideraciones sobre la admisión del principio de oportunidad en el proceso civil, puestas a la luz del sistema constitucional español encuentran reflejo en el reconocimiento de la propiedad privada y de la libertad de empresa -arts. 33 y $38 \mathrm{CE}-$ los cuales involucran de forma directa a la autonomía de la voluntad, y que a su vez representan una manifestación del orden público económico. Así, en tanto el proceso penal tiene por punto central el derecho a la libertad, el civil, tiene por centro de atracción la propiedad ${ }^{31}, \mathrm{y}$ en consecuencia, por el reconocimiento estatal del haz de facultades subjetivas privadas que nacen de esa correlación de elementos constitucionales, el particular, también se encuentra en condición legal de libre elección respecto de las relaciones jurídicas en las que quiere ser parte, y el momento y forma para la defensa de las facultades que a tal posición jurídica sea propia, puesto que todo derecho subjetivo implica ejercicio en propia persona y respaldo institucional del Estado.

La precedente exposición sobre la admisión del principio de oportunidad en el proceso civil también tiene eco en el texto constitucional nicaragüense a partir del contenido de los artículos 5, 44 y 99. El primero de los citados artículos, dispone el reconocimiento de todas las formas de propiedad; el 44 dispone garantía estatal respecto a la propiedad privada, y el 99, determina la libertad de empresa al considerar que los particulares son los artífices de la actividad económica. También se pueden señalar en este punto otro tipo de derechos subjetivos que potencialmente serían susceptibles de constituir la causa petendi en un proceso, pero que carecen de contenido patrimonial. En tal sentido podrían citarse, a manera de ejemplificación en el ordenamiento nicaragüense, el derecho a la vida -artículo 25-, al honor-artículo 26-, a la formación de una familia por medio del matrimonio o de la unión de hecho estable -art.72-, y la serie de relaciones que en orden al estado civil de la persona. Cuestiones éstas últimas, que incidirán en considerar que hay supuestos en que el principio de oportunidad en sus

29 Lo cual quizá sea consecuencia de lo que la doctrina ha entendido como aproximación y dilución de la nitidez diferencial entre el proceso civil y el penal. V. T. ARMENTA DEU, Lecciones de Derecho Procesal Penal, Madrid, 2016, p. 34.

30 J. MONTERO AROCA, La prueba., cit. pp. 26, 472.

31 J. MONTERO AROCA, J. L. GÓMEZ COLOMER, S. BARONA VILAR, Derecho jurisdiccional, parte general, Valencia, 2015, p. 231 y ss. J. MONTERO AROCA, La prueba., cit., pp. 26, 472. No obstante lo dicho por el autor, si bien es cierto que la propiedad constituye uno de los puntos fundamentales de relación entre los sujetos de Derecho, también lo es que existen otros tipos de relaciones jurídicas particulares, que pese a ser erigidas con fundamento en la autonomía privada, no necesariamente tienen como centro de atracción lo patrimonial, piénsese por ejemplo en las relaciones jurídicas relativas a los derechos de la personalidad, las relativas al estado civil o bien de relaciones familiares, pese a la especialización sustantiva y procesal que este último punto ha ido adquiriendo progresivamente en algunos ordenamientos en los que existe legislación procesal y sustantiva. 
manifestaciones derivadas, no es admisible sin ninguna reserva, cuestión que requeriría atención detenida, y que por razón del objeto de este trabajo hemos de omitir.

En definitiva, la anterior configuración legislativa del principio de oportunidad referido al ámbito civil, hace posible su admisión en esta parcela jurídica pese a que ni tan siquiera se aluda textualmente a él en la legislación especial de la materia ${ }^{32}$.

A continuación se presentan los principios vinculados al derecho a utilizar los medios de prueba, que se pueden entender como una derivación del antes expuesto principio, ellos son el principio dispositivo y el de aportación de parte.

\subsection{Dispositivo}

En la explicación conceptual de este principio - como también en el que se tratará en el siguiente apartado-, late de forma primordial, la noción de "interés" respecto de aquellos ámbitos que el ordenamiento jurídico reconoce como manifestación de la autonomía de la voluntad de los particulares ${ }^{33}$. No ya en orden a la creación de las relaciones jurídicas, sino de cara a requerir del Estado por medio de los tribunales, la tutela del contenido material de los derechos subjetivos.

Por este principio procesal se ha de entender que en todo sujeto de Derecho, se reconoce la libertad, tanto para iniciar el proceso, como para finalizarlo en dependencia de sus intereses ${ }^{34}$. En tal sentido, la doctrina coincide en que la expresión puntual de dicho principio se puede sintetizar en los siguientes puntos ${ }^{35}$ :

a. El particular, como sujeto que determina su ámbito jurídico privado, tiene libertad de incoar el proceso de acuerdo a la conveniencia de sus intereses. Consecuencia de ello, el Estado se halla impedido de iniciar un proceso ex oficio -"nadie puede ser obligado a ejercitar su acción" ${ }^{36}$.

32 J. MONTERO AROCA, La Prueba., cit., p. 472. sostiene que constituye un principio "determinante" dentro del proceso civil, pese a que la LEC, únicamente hace alusión a los principios que derivan de aquél. Para el Derecho nicaragüense, puede verse los principios del proceso civil, en W. Tórrez Peralta, Derecho procesal civil. Conforme al nuevo Código Procesal Civil, Managua, 2015, pp.80 y 87.

33 Como ya se ha dejado advertido, en este punto ha de tenerse en cuenta que también por medio de la autonomía privada se crean algunos tipos de relaciones jurídicas cuyo contenido material escapa a la calificación de patrimonial. En tal tipo de relaciones, pese a que en su constitución el ejercicio de la autonomía privada sea absolutamente indispensable, el sujeto no puede alterar el contenido de los deberes y derechos que de tales surgen, como sucede por ejemplo con manifestaciones del estado civil de la persona.

34 Arts. 12 y 96 CPCiv.

35 J. MONTERO AROCA, J. L. GÓMEZ COLOMER, S. BARONA VILAR, Derecho jurisdiccional., cit., p. 231. J. D MORENO, Introducción al sistema judicial español. Organización judicial, proceso civil, Madrid, 2013, p. 136 s. C. RUÍZ DE LA FUENTE, "El principio dispositivo y las intimaciones judiciales en la prueba", en, J. Picoy I Junoy (Dir.), Principios y garantías procesales: Liber Amicorum en homenaje a la profesora María Victoria Berzosa Francos, Barcelona, 2013, pp. 197 s. J. MONTERO AROCA, La Prueba..., cit., p. 473. I. ESPARZA LEIBAR, El principio del debido proceso, Barcelona, 1995, p. 33.

36 I. ESPARZA LEIBAR, El principio..., cit., p. 33. 
b. Corresponde a las partes la fijación procesal del o los intereses que pretenden les sean tutelados, esto es la concreción efectiva de cuál es el objeto del proceso y del debate -determinación de la pretensión y de la resistencia-.

c. Las resoluciones y especialmente la sentencia pronunciada por los órganos jurisdiccionales han de guardar de forma escrupulosa, una lógica coherencia con los puntos de debate propuestos por las partes.

d. El Derecho reconoce que las partes procesales tienen la potestad-que constituye el reverso del punto a)- de abandonar la continuación del proceso como manifestación de la disponibilidad de sus intereses ${ }^{37}$. Salvo en aquellos supuestos en los que los intereses sean del tipo que antes hemos esbozado como tendentes a derechos subjetivos cuya disposición no corresponde de forma exclusiva al particular ${ }^{38}$.

\subsection{Principio de aportación de parte}

Como manifestación secuencial de los principios antes expuestos, se presenta el de aportación de parte, el cual puede explicarse como la necesidad de que los contendientes procesales expongan los hechos al amparo de los cuales tienen por fundadas sus reclamaciones - pretensiones y resistencias-, por ello se ha dicho ${ }^{39}$ que este principio da pie a la existencia de los brocardos, da mihi factum dabo tibi ius, y, iudex iudicare debet secundum allegata et probata partibus, de conocida aplicación en la práctica forense.

37 V., arts. 19 a 22 LEC y arts. 96 a 108 CPciv.

38 Así lo reconoce J. D. MORENO, Introducción al sistema..., cit., pp. 137 s.: Se dan casos, en los que están en juego intereses que no están sometidos al principio de la autonomía de la voluntad y por lo tanto tienen un objeto no disponible por los litigantes. En esta situación se encuentran los procesos donde el interés del Estado en la tutela de determinados derechos prevalece sobre cualquier otra clase de consideración. Esta situación se advierte con claridad en los litigios donde están involucrados intereses de menores o incapacitados o en aquellos otros procesos que afectan al estado civil de las personas, tales como los de maternidad, paternidad o filiación. Por eso, para distinguirlos del resto, a este tipo de procesos civiles se les da el nombre de procesos civiles no dispositivos. El proceso civil no dispositivo se utiliza por lo general en aquellos supuestos en que la tutela del derecho que se pretende conseguir sólo puede obtenerse a través de los jueces, que es la única manera que el interés del Estado quede garantizado, impidiendo que las partes puedan realizar actos que puedan llegar a afectar a intereses públicos que mediante el mismo se tratan de proteger. En este tipo de procesos, la acción que se ejercita es en general de naturaleza constitutiva y se caracterizan porque en la elaboración del material del hecho que sirve de base a la pretensión [Cortés Domínguez] no queda sólo en manos del demandante sino que se confiere una participación importante al juez y al ministerio fiscal (STC 185/2012). Así pues, lo que define a este tipo de procesos civiles es el carácter indisponible de su objeto, siendo así que, por este motivo, y para cumplir con eficacia el cometido que la ley le asigna, es preciso que los jueces gocen de mayores poderes que en los demás procesos con el propósito de permitirle descubrir la verdad que se oculta realmente tras la controversia [Planck]. En tal sentido podría V. arts. 12 CPCiv, que establece el derecho de las partes para iniciar y poner fin al proceso en cualquier instancia, o en el recurso extraordinario de casación, dejando a salvo los supuestos de procesos en los que se tutelan derecho o intereses públicos. Y 96 CPCiv que sustrae de la disposición de los particulares los supuestos en que legislativamente se determine por razones de orden público, de interés general, de protección de terceros, o cuando implique fraude de ley.

39 J. L. SEOANE SPIEGELBERG, La prueba en la Ley de Enjuiciamiento..., cit., p. 22. 
Lo anterior parece plantear una cierta identificación del contenido de este principio con el punto $b$ que se expuso arriba como consecuencia del principio dispositivo, creemos que tal cuestión no contradice lo antes expresado.

Precisamente, en la exposición del punto anterior se dijo que las partes tienen por imperativo legal, la necesidad de concretar la fijación procesal del o los intereses que pretenden les sean tutelados, esto es la concreción de cuál es el objeto del proceso y del debate -lo que se ha dado en llamar hechos relevantes-, distintos de "todos los demás" hechos ${ }^{40}$, que son los denominados impeditivos y extintivos ${ }^{41}$, que son los hechos a que se refiere este principio procesal de aportación de parte.

En consecuencia, el principio de aportación de parte tiene como contenido, en primer lugar el deber de ambas partes de traer al proceso los hechos, según se ha explicado antes, y la entera asunción de la carga de la prueba de todo cuanto afirman ${ }^{42}$ según la posición jurídica que cada uno ocupe en el proceso, en segundo término ${ }^{43}$.

40 Para esta explicación V. J. MONTERO AROCA, J. L. GÓMEZ COLOMER, S. BARONA VILAR, Derecho jurisdiccional..., cit., p. 233.: El principio de aportación de parte atiende a la aportación de hechos al proceso (no a los hechos determinantes del objeto del mismo, sino todos los demás) y a los medios de prueba para acreditar todos los hechos afirmados por las partes. Es un principio distinto del anterior, y sobre el mismo ha incidido básicamente la que se ha llamado publicización del proceso civil ( ).

41 Téngase en cuenta que junto a las excepciones procesales, en la LEC española, se ubican las de tipo material, consistentes en hechos nuevos que aporta el demandado. Entendiendo como hechos nuevos las alegaciones que no tienen por objeto una declaración judicial sobre una causa petendi distinta a la deducida en la demanda -en caso contrario darían lugar a una reconvención-, no suscitan objeto procesal nuevo y su objeto es simplemente pedir la absolución, no pidiendo nada positivo frente al actor -ej. Paradigmático: la prescripción-. J. MONTERO AROCA, J. L. GÓMEZ COLOMER, A. MONTÓN REDONDO, El nuevo proceso civil, Valencia, 2.000, pp. 381-382. Este tipo de excepciones se clasifican entre propias e impropias. Las impropias encuentran su fundamento en "hechos impeditivos" y "extintivos". Los primeros se producen de forma concurrente o coetánea con los que el actor utiliza para fundar su pretensión, por lo cual constituyen impedimento para que tales hechos tengan eficacia -vicios del consentimiento, falta de capacidad-. Por su parte, los segundos, o extintivos, constituyen situaciones o hechos que se verifican de forma posterior a aquellos en los que el actor se apoya en su demanda-constitutivos-y por ello tienen la virtualidad de suprimir o extinguir la virtualidad de aquéllos -ej. El pago-. J. R. MEDINA CEPERO, El tratamiento procesal penal de la prescripción del delito, Madrid, 2002, p. 89. En lo fundamental, V. la explicación que sobre hechos que pueden contenerse en el objeto del debate se expone en: J. MONTERO AROCA, La Prueba..., cit., pp., $31 \mathrm{~s}$.

42 Pese a que el texto del artículo $24 \mathrm{CE}$, pudiera ser interpretado en el sentido de que el derecho a la prueba está dispuesto de forma exclusiva al demandado, por el uso que en dicho texto se realiza del término "defensa", se ha de entender que corresponde a las dos partes procesales, puesto que el citado término alude a los intereses que los litigantes defienden y no a una concreta posición dentro del proceso. han establecido en el proceso a efectos de su defensa. En tal sentido la STC 175/1994, de 7 de junio, f. J. $4^{\circ}$, explica que el derecho a la defensa contradictoria de las partes contendientes, es de aplicación en cualquier proceso, y por eso, se les debe brindar la oportunidad de alegar y probar procesalmente sus derechos, X. ABEL LLUCH, J. PICÓ I JUNOY, Problemas actuales de la prueba Civil, Barcelona, 2005, p. 30.

43 V. C. FONS RODRÍGUEZ, J. PRAT I RUBI, "El principio de adquisición procesal: los hechos y su falta de prueba", en, J. Picoy I Junoy (Dir.), Principios y garantías procesales: Liber Amicorum en homenaje a la profesora María Victoria Berzosa Francos, Barcelona, 2013, pp. 88, 89. 


\section{OBJETO Y FUNCIÓN DE LA PRUEBA JUDICIAL}

De entre los puntos explicativos del fenómeno jurídico de la prueba, atrae la atención los elementos de su funcionalidad dentro del proceso judicial, en atención a lo cual desarrollamos a continuación los puntos relativos a su objeto y a la finalidad a que debe enderezarse.

\subsection{Los hechos. Elementos fundamentales en el tema de la prueba}

Es sabido que una vez que las partes han expuesto ante el órgano judicial los hechos en que fundamentan sus peticiones se hace absolutamente necesario que cada una de ellas convenza al juez de que tales hechos se han verificado, y por tanto, deben incidir en la decisión que sobre el pleito se vaya a adoptar. Esto es que sobre demandante y demandado recae la necesidad de mostrar que existen razones lógicas para acoger o no los hechos que fundamentan sus peticiones, dicho de otra forma, tienen el deber de probar los extremos de sus alegaciones fácticas ${ }^{44}$, de conformidad con el principio de aportación de parte. Nótese aquí la relación entre este punto y las nociones que expone el Tribunal Constitucional español en torno a una de las aristas del concepto tutela judicial efectiva explicada en la introducción de este trabajo, específicamente la relativa al significado de la "motivación" de las resoluciones judiciales.

No obstante lo dicho ¿la actividad probatoria debe realizarse en relación con todos los hechos aportados por las partes? La respuesta es que la prueba no recae sobre todos los hechos. Una vez que el demandante de forma unilateral realiza sus argumentaciones fácticas a través de la demanda, corresponderá al demandado conocerlas y por tanto, aceptarlas u oponerse a la certeza de las mismas, en este último caso, se estarían fijando posiciones antagónicas respecto del valor de los hechos. Como ha dicho la doctrina ${ }^{45}$, se fija así el tema de prueba, lo que debe probarse: los hechos afirmados por una parte que la otra rechaza. Los hechos controvertidos. Pero ¿qué debe entenderse por "hechos" a efectos del proceso?

En una primera aproximación semántica, hecho, deriva de la palabra latina factus -hecho, de hacer-: y cuenta en el Diccionario Académico, con la acepción 4a: "acción u obra", y la 5a: "cosa que sucede".

Según el Diccionario del español jurídico ${ }^{46}$, en plural "hechos", significa el conjunto de circunstancias fácticas en las cuales se funda una resolución o un escrito de parte. Por lo cual guarda relación con la frase "hechos probados", que traduce el sig-

${ }_{44}$ Afirmación que encuentra su reflejo en el texto del artículo 231 CPCiv “A través de los medios de prueba, las partes acreditarán las afirmaciones de hecho alegadas que sean controvertidas, convencerán a la autoridad judicial de la verdad o certeza de un hecho, o lo verificarán como cierto a los efectos del proceso. Y en los arts. 281.1 y 216 LEC.

45 J. MONTERO AROCA, J. L. GÓMEZ COLOMER, S. BARONA VILAR, Derecho jurisdiccional., cit., p. 239. J. MONTERO AROCA, La Prueba..., cit., pp. 33, 72. V. art 281.3 LEC. y, art. 235 CPCiv, que disponen la regla de exención de la prueba respecto de los hechos sobre los cuales haya plena conformidad de las partes.

46 Consultado en: http://dej.rae.es/\#/entry-id/E132830, el 17 de febrero de 2017. 
nificado de un relato histórico de los sucesos objeto de enjuiciamiento tenidos como ciertos por el órgano judicial.

Ambas aproximaciones lingüísticas hacen notar que los hechos son acontecimientos empíricos, sucesos, manifestaciones de la realidad que de alguna forma inciden en la vida de las personas. Parece que en principio en el proceso, un hecho tiene directa relación con una experiencia meramente empírica aportada al proceso como fundamento de lo que cada parte pide al órgano judicial para sí.

Sin embargo, pese al aparente significado antes establecido, no puede escapar a la consideración de que dentro del proceso no es posible reproducir los acontecimientos planteados por las partes, sino que de ellos se da cuenta por medio del lenguaje, en ejercicio de una actividad narrativa que procura presentar una imagen, una impresión mental de la forma en que lo acontecido realmente se produjo ${ }^{47}$, trayendo cada una de las partes al proceso esa narración o descripción con el objetivo de que sirva como argumento útil a sus intereses, y si por argumento entendemos en toda su dimensión significativa, el razonamiento útil para probar o demostrar una proposición, o para convencer de lo que se afirma o se niega (DRAE), finalmente es posible deducir que los "hechos" planteados tanto por el demandante como por el demandado, eso que las legislaciones consideran que debe ser acreditado ante el juez por medio de la prueba, no es más que la descripción de los mismos realizada de forma argumental ${ }^{48}$.

Por ello, se ha dicho que la noción procesal del hecho, no constituye el hecho como tal "ocurrencia de la realidad empírica", sino, "enunciados" relativos a dichas ocurrencias pues tales hechos del mundo real responden a modalidades empíricas que son totalmente independientes de las determinaciones conceptuales, valorativas o normativas que a ellos se refieren. Realmente, lo que se aporta al proceso como hechos, son enunciados referidos al mundo real, versiones -interesadas por lo general- de la realidad o experiencia que resultan relevantes para la decisión del proceso. En consecuencia, en el proceso "el hecho" es en realidad lo que se dice acerca de un hecho, la enunciación sobre él, no el "objeto empírico que es enunciado ${ }^{49}$.

Concretamente, en torno a los hechos es que gira la labor probatoria. Así pues, hecho y prueba constituyen un binomio inescindible puesto que la convicción judicial se formará por medio de la acreditación de lo que las partes afirman sobre los hechos.

47 M. GASCÓN ABELLÁN, Los hechos en el Derecho. Bases argumentales de la prueba, Madrid, 2010, p. 49. Afirmar la verdad de los enunciados fácticos no es una cuestión trivial. Primero, porque el juez no ha tenido acceso directo a los hechos, de modo que lo que inmediatamente se conoce son enunciados sobre los hechos, cuya verdad hay que acreditar.

48 M. SERRA DOMÍNGUEZ, “arts. 1214 a 1253”, en, M. Albaladejo García, S. Díaz Alabart (dir.), Comentarios al Código Civil y Compilaciones forales Tomo XXVI, Vol. II, Madrid, 1991, pp. 35 s. J. MONTERO AROCA, La Prueba..., cit., p. 65, expone que, a CARNELUTTI le corresponde haber sido el primer autor procesalista en plantear que es a las afirmaciones sobre los hechos y no a los hechos mismos que debe dirigirse la prueba. Con los cual se denota que para dicho autor, lo que las partes aducen en el proceso, no son los hechos mismos, sino más bien, su descripción.

49 M. TARUFFO, La prueba de los hechos, traducción de J. Ferrer Beltrán, Madrid, 2011, pp. 113, 114. 


\subsection{El objeto de prueba}

Por lo antes expresado y aceptado, resulta lógico entender que el objeto de la prueba, lo que debe ser acreditado como acaecido efectivamente son las afirmaciones por medio de las que las partes describen la ocurrencia de la situación jurídica de que se trate. No obstante, dichas afirmaciones se refieren a los hechos acaecidos y por tanto tales hechos deben poder avizorarse o emerger explicitados de lo que sobre ellos se expresa.

Si legal y doctrinalmente se utiliza la noción "objeto de la prueba" como expresión de aquel aspecto de la realidad empírica a la cual se atribuye una determinada consecuencia jurídica, parece lógico aceptar que en dicha expresión se esconde el significado de "realidades", que pueden estar en relación con la mente y voluntad humanas, o constituir meros hechos naturales.

Por medio de la prueba, entonces, las partes hilvanan los razonamientos y justificaciones a fin de que por medio de tales se construya un fundamento razonable para sus peticiones, cuestión que al mismo tiempo, contribuye a que los hechos emerjan y se revelen a partir de lo que sobre ellos se afirma de una forma más o menos evidente ante la mente del juzgador.

Dicho lo anterior, también se entiende que la literatura sobre proceso civil sostenga que como objeto de la prueba se ha de tener todo tipo de conducta humana ya sean voluntarias o involuntarias, los hechos naturales, toda realidad tangible acaecida con o sin intervención humana, la persona humana y sus estados anímicos o psicológicos ${ }^{50}$, en fin, lo que es posible acreditar como realmente sucedido ${ }^{51}$.

\subsection{Función de la prueba}

El último punto de este trabajo se ha dedicado a presentar brevemente, la relación entre "hechos" y "verdad" que subyace en el tema de la prueba judicial, en razón de que a propósito de la prueba se produce una interrelación entre, la realidad ontológicamente entendida y los esquemas formales del Derecho cuya síntesis debe tener como resultado la determinación judicial de qué posición procesal ha sido acreditada de mejor manera. Ello, a efectos de conceder lo solicitado, cuestión que constituye imperativo dirigido al órgano judicial por el Derecho moderno de corte garantista, por mor de los derechos fundamentales implicados en el proceso.

La función de la prueba se circunscribe dentro de las aplicaciones posibles del resultado del proceso en general, toda vez que constituye la ratio, la medida en la que únicamente cabrá tener como "adecuada" la decisión judicial. Esto es que por imperativo constitucional - en el que de forma mediata se encuentra el derecho a

50 Exposición que realiza, J. MONTERO AROCA, La Prueba..., cit., p. 66, citando a H. DEVIS ECHANDÍA, H, Teoría general de la prueba judicial t. I; Bogotá, 2002, pp.150 ss.

${ }_{51}$ El objeto de la prueba son los hechos relevantes: L. PRIETO-CASTRO Y FERRÁNDIZ, Tratado de derecho procesal civil T. II, Pamplona, 1985, p. 621. Las afirmaciones que las partes realizan sobre los hechos objeto del proceso. A. DE LA OLIVA SANTOS, Derecho procesal civil, vol. II, Madrid, 1990, p. 269. 
la seguridad jurídica- los jueces tienen el deber de exponer las razones de que se valieron para resolver en determinado sentido ${ }^{52}$. Así, la relación de este punto con la función jurisdiccional, resulta ser que la prueba es el elemento estructuralmente esencial para la construcción de la motivación ${ }^{53}$ de las sentencias, y subyacentemente responde a una de las derivaciones conceptuales o materiales necesarias que hacen posible la concreción de la tutela judicial efectiva.

\subsubsection{La verdad como elemento de descubrimiento y de justificación -de motivación-}

La necesaria demostración de los hechos dentro del proceso no obedece a la mera satisfacción de un prurito intelectual de conocimiento "en estado puro" sobre los hechos empíricos, sino a la aportación de material informativo útil para la solución de controversias relativa a un determinado derecho; "no se pretende determinar el hecho en sí mismo sino en la medida en que éste es el presupuesto para la aplicación de normas en el caso concreto" ${ }^{54}$.

Por ello, la actividad probatoria ubica al juez dentro de los esquemas generales de todo conocimiento: el juez, sujeto cognoscente, se ubicará frente al objeto -de conocimiento, los hechos aportados-y de ello obtendrá una determinada representación mental. Ese proceso cognitivo, en el caso que nos ocupa, no puede enderezarse a otro objeto que el establecimiento de la verdad, a efectos de la configuración de las situaciones jurídicas planteadas por las partes que hará posible, negar unas y admitir otras. Pero ¿qué verdad es lo que constituye la función de la prueba?

Efectivamente, hablar de "verdad", a secas, refiere a un concepto que quizá escapa a una concreción absoluta pues implicaría un tratamiento detenido desde la perspectiva de la teoría del conocimiento y sus manifestaciones. Por ello, al margen de dicha discusión, y en pos del logro del objeto de este breve trabajo, nos centraremos en la noción planteada desde la filosofía jurídica como aproximación al tema.

A propósito de la verdad en el proceso, se ha expresado ${ }^{55}$ que no puede considerarse que su consecución sea la función del proceso -y por tanto, tampoco de la prue-

52 Art.120.3 CE; art. 34.8 Cn. Un tratamiento pormenorizado sobre la motivación de las resoluciones judiciales, desde su génesis histórica hasta las implicaciones actuales en el Derecho español, en especial, la relación entre motivación judicial y su relación con las teorías de la argumentación jurídica, en, T. J. Aliste Santos, La motivación de las resoluciones judiciales, Madrid, 2011.

${ }_{53}$ Sobre dicha relación V. X, ABEL LUCH, J. PICÓ I JUNOY, Objeto y carga de la prueba, Barcelona, 2008, p. 30. Exigirá determinar qué hechos han resultado probados y en virtud de qué pruebas.

54 M. TARUFFO, La prueba de los hechos..., cit., p. 90.

55 V. T. ARMENTA DEU, Lecciones de Derecho procesal Civil..., cit., p. 169. J. MONTERO AROCA, La prueba..., cit., p. 42. Para mayor ilustración de lo dicho, basta con revisar lo que MONTERO AROCA, en la obra antes citada -pág. 49 a 53-, plantea como razones para el rechazo de la "verdad materia" u objetiva como función de la prueba judicial: consiste en una narración de los modelos de investigación judicial utilizado por los regímenes de ideología totalitaria, tanto en el ámbito socialista como fascista. En lo que se expresa por dicho autor, no se hace abstracción de los elementos de pura política legislativa y su relación con la ideología política, a efectos de anular 
ba-, no obstante, las razones que desde la perspectiva histórica se exponen como fundamento de ello, no parece responder a un análisis epistemológico del tema, sino más bien, a uno de tipo histórico-formal que carga el análisis de modelos en los que la "verdad" es más bien lo que el juez investigaba para lograr el convencimiento. Con ello, lo que se obtiene es una confusión entre la forma en que tal actividad se llevaba a efecto, con la finalidad -siempre loable-de alcanzar la verdad de los hechos.

Si la noción procesal de verdad se liga necesariamente -desde el aspecto lingüístico- a la existencia de un juicio o proposición que no se puede negar de forma racional, sostener lo antes afirmado resultaría un sinsentido, en primer lugar porque ello implicaría para las partes la necesidad de aportar al juicio, los hechos en estado puro -cuestión que ya se explicó antes no sucede en el proceso-, puesto que en verdad, de lo que las partes se quejen uno frente al otro, será siempre de actuaciones o hechos que han acaecido con anterioridad al proceso respecto de lo cual simplemente realizarán una suerte de reconstrucción argumental -a través de proposicionesacorde a su capacidad discursiva de descripción de los mismos. Y en segundo lugar, porque no sería lógico permitir la revisibilidad de las resoluciones ${ }^{56}$.

Además, se debe tener presente, que el concepto de "verdad" no corresponde a una categoría puramente jurídica, sino más bien extraprocesal que se produce en el mundo social, manifestación de una realidad sobre objetos o fenómenos efectivamente producida o acaecida, es decir, fijado de forma históricamente determinada, y por ello, se interroga si es a ésta verdad absoluta a la que se ha de dirigir la actividad probatoria dentro del proceso.

Una respuesta a dicha duda ha sido propuesta por la doctrina procesalista al identificar entre "verdad material", entendida en el sentido naturalístico, coincidencia exacta con lo históricamente ocurrido en la realidad, obtenida por medio de "instrumentos cognoscitivos distintos de las pruebas judiciales" ${ }^{57}$; y "verdad formal", que es aque-

la posibilidad de que la prueba deba tender al establecimiento de la verdad. Como suele ocurrir en la generalidad de la doctrina procesal, se llega a mencionar que si bien es cierto no se puede abandonar del todo que de la prueba tienda al establecimiento de una verdad, ésta siempre será resultado de la actividad reglada que se circunscribe dentro de cada ordenamiento jurídico, por lo cual siempre será necesario considerar que "no puede desconocerse que en el proceso y en la prueba tiene normalmente que existir un intento decidido de verificar de la manera posible más próxima a la verdad las afirmaciones de hecho que realizan las partes".

56 No obstante que la búsqueda de verdad sobre los hechos se realice tanto por las ciencias naturales o exactas, como por la ciencia jurídica a través del proceso, por medio de la prueba, ello no impone que ambos esquemas de análisis tengan que ser idénticos. El científico busca la verdad a través de pruebas que se someten en su racionalidad a las características de los métodos cognoscitivistas propios de esos campos, en cambio, la prueba judicial posee su propio carácter distintivo como consecuencia de dos elementos: 1. La presencia de regulación jurídica de la prueba y 2) el hecho de que sirve para usos típicamente jurídicos, en contextos jurídicos como el proceso. La prueba se puede, en realidad, definir como jurídica si concurre al menos una de estas dos condiciones (aunque habitualmente concurren ambas): M. TARUFFO, La prueba de los hechos..., cit., pp. 31, 342.

57 Como dice J. FERRER BELTRÁN, prueba y verdad en el derecho, Madrid, 2002, p. 69: La verdad material es aquella de que se habla fuera del proceso judicial...la ocurrencia de los hechos cuya existencia se afirme o de la no-concurrencia de los hechos cuya existencia se niegue. 
lla verdad o evidente conclusión que resulta del proceso a través de los mecanismos probatorios. Esta distinción también corresponde a la de "verdad absoluta", explicada por la verdad material y "verdad relativa", que se explica por la segunda noción antes expuesta $^{58}$. Con lo cual, se ha pretendido separar la prueba de la verdad.

Aunque si lo que se quiere decir con que la función de la prueba y por tanto del proceso, no es establecer la verdad, sino resolver un conflicto y por ello, la llamada verdad formal es la meta del proceso a través de la prueba, lo que hoy no resulta lógico es pretender que la verdad y la prueba no son conceptos concomitantes.

La anterior distinción ha sido criticada por cuanto en el estado actual del Derecho garantista, y frente a los principios de tutela judicial y seguridad jurídica que se realizan por medio de la jurisdicción -art.34.4 y $34.8 \mathrm{Cn}$.-, resulta evidente que no es posible pretender que se separe tajantemente la verdad judicial de la verdad concreta por motivo de ser fruto del proceso a través de las pruebas -elementos formales-; en todo caso, como ha dicho TARUFFO ${ }^{59}$, el elemento técnico jurídico antes mencionado, sólo vale para no pretender alcanzar una verdad absoluta, pero no para diferenciar totalmente la verdad que se establece en el proceso de aquella de la que se habla fuera del mismo, pues equivaldría a sostener que existe un concepto autónomo de verdad procesal, que no parece posible.

Así, se acepta que la verdad que corresponde a la función de la prueba, es una de tipo relativa, pero no porque se separe tajantemente de la realidad material y se determine únicamente por medio de lo que las partes refieren sobre los hechos concretos, es relativa, puesto que en la dinámica de su desarrollo, en primer lugar se han de tener presente las normas propias de su estatuto dentro de cada ordenamiento jurídico, y además, por la relatividad del contexto ${ }^{60}$

Esta es precisamente la verdad que se cree inalcanzable, al menos en muchas ocasiones, en el proceso judicial. La verdad formal, en cambio, es aquella que se obtiene en el resultado de la actividad probatoria puede coincidir o no con la material (aunque a menudo se admite que es deseable que lo haba), pero sería aquélla la que gozaría de autoridad jurídica. Con independencia de la coincidencia con los hechos realmente ocurridos, se atribuye la calificación de verdadera formalmente a la declaración de hechos probados realizada por el juez o tribunal en la sentencia.

58 M. TARUFFO, La prueba de los hechos..., cit., p. 24.

59 M. TARUFFO, La prueba de los hechos..., cit., p. 25.

60 Como lo explica M. TARUFFO: pese a que las reglas procesales determinan algunos aspectos del modo en que la verdad de los hechos es establecida -admisión, medios, valoración, oportunidad, etc.- que sirven como tamices para filtrar la veracidad de los hechos -límites a los instrumentos cognoscitivos que se pueden emplear para determinarla-, ello no es suficiente para concebir totalmente distinta la verdad "que se obtiene con tales interferencias, respecto de la que acaece fuera del mismo", máxime si tal verdad debe, como parece, establecerse de forma controlable por medio de criterios lógicos y epistemológicos. Tanto la verdad que se forma en el proceso, como la que acaece fuera del mismo, son relativas -al menos mientras se piense en la verdad empírica de aserciones concernientes a sucesos materiales-. Por lo que hace a la condición de relatividad de la verdad procesal por razón del contexto, se explica que para alcanzar tal verdad, se ha de considerar el conjunto de elementos referenciales del entorno socio cultural en el que el proceso se desarrolla. Ello se deduce de la referencia que el citado autor realiza de los "marcos de referencia mediante los que se construyen versiones de los hechos", que lo llevan a concluir que "la verdad procesal es ciertamente relativa, dado que está determinada en función del marco de referencia constituido por el proceso y por las 
Las determinaciones legales que el Código Procesal Civil -y los correspondientes de la LEC-, dispone en los artículos 13 -la prueba debe servir para la acreditación de hechos controvertidos, 201, 251 -la motivación de las sentencias tendrán como fundamento los razonamientos fácticos y jurídicos obtenidos de una lógica y racional valoración de las pruebas a través de la sana crítica, el conocimiento y criterio humano, de acuerdo a las normas que rigen el razonamiento lógico-, no pueden referirse más que a la verdad entendida en el sentido antes propuesto. Más específicamente a la llamada "fijación de los hechos" realizada a través de la verdad relativa. He aquí la relación entre "verdad" descubierta y justificada, entendida en el sentido antes expuesto, con el proceso y sus modernas exigencias garantistas.

Finalmente, luego de haber expuesto los puntos contenidos en este trabajo estamos en condiciones para afirmar que, la verdad de los hechos constituye la materia esencial para la verificación efectiva de la tutela judicial efectiva que los modelos legislativos modernos - en el caso estudiado español y nicaragüense- adoptan como manifestación del respeto a la dignidad de la persona. Derecho que se concreta en la dinámica procesal por medio del ejercicio del derecho fundamental a utilizar los medios de prueba.

\section{BIBLIOGRAFÍA}

ABEL LLUCH, X. J.PICÓ I JUNOY, (coord.); Problemas actuales de la prueba Civil, Barcelona, 2005.

ABEL LUCH, X. J. PICÓ I JUNOY, Objeto y carga de la prueba, Barcelona, 2008.

ARMENTA DEU, T., Lecciones de Derecho Procesal Penal, Madrid, 2016.

ARMENTA DEU, T. Lecciones de Derecho procesal civil. Proceso de declaración, proceso de ejecución y procesos especiales, Madrid, 2013.

ESPARZA LEIBAR, I. El principio del debido proceso, Barcelona, 1995.

FERRAJOLI, L. Los fundamentos de los derechos fundamentales. Debate con Luca Baccelli; Michelangelo Bovero; Riccardo Guastini; Mario Jori; Anna Pintore; Ermanno Vitale; Danilo Zolo, edición de Antonio de Cabo y Gerardo Pisarello, Madrid, 2009.

FERRER BELTRÁN, J. Prueba y verdad en el Derecho, Madrid, 2002.

FLORES MENDOZA, I. "El porvenir de la ciencia jurídica. Reflexión sobre la ciencia y el Derecho", en, Instituto de Investigaciones jurídicas de la Universidad Autónoma de México, La ciencia del Derecho durante el siglo XX, México D. F, 2004.

FONS RODRÍGUEZ, C. J. PRAT I RUBI, "El principio de adquisición procesal: los hechos y su falta de prueba”, en, J. Picoy I Junoy (Dir.), Principios y garantías

normas que lo regulan (en particular aquellas que se refieren a las pruebas y a la determinación de los hechos) y se sitúa, pues, inevitablemente dentro del "vocabulario" del proceso, es decir, del lenguaje y de la cultura típica de la administración de justicia....(p. 76)...en resumen: la regulación legal del proceso y de las pruebas no es de por sí un obstáculo para que se determine la verdad de los hechos en el proceso, supuesto que se trata inevitablemente de una verdad relativa y ligada al contexto en el que es establecida".: La prueba de los hechos..., cit., pp. 72-79. 
procesales: Liber Amicorum en homenaje a la profesora María Victoria Berzosa Francos, Barcelona, 2013.

GASCÓN ABELLÁN, M. Los hechos en el Derecho: Bases argumentales de la prueba, Madrid, 2010.

GUTIÉRREZ-ALVIZ, F. MORENO CATENA, V. “Artículos 113 a 127 de la Constitución Española de 1978”, en O. Alzaga Villaamil, F Fernández Segado (dirs.), Comentarios a la Constitución Española Tomo IX, Madrid, 2006.

MEDINA CEPERO, J. R. El tratamiento procesal penal de la prescripción del delito, Madrid, 2002.

MONTERO AROCA, J. La prueba en el proceso civil, Pamplona, 2005.

MONTERO AROCA, J. J. L. GÓMEZ COLOMER, S. BARONA VILAR, Derecho jurisdiccional, parte general, Valencia, 2015.

MONTERO AROCA, J. J. L. GÓMEZ COLOMER, A. MONTÓN REDONDO, El nuevo proceso civil, Valencia, 2000.

MORENO, J. D. Introducción al sistema judicial español. Organización judicial, proceso civil, Madrid, 2013.

OLLER SALA, M. D. "El derecho a la utilización de los medios de prueba como factor de dinamización del derecho probatorio", en, X. Abel Lluch, J. Picó I Junoy, M. Richard González (directores), La prueba judicial. Desafíos en las jurisdicciones civil, penal, laboral y contencioso administrativa, Madrid, 2011.

PICÓ I JUNOY, J. El derecho a la prueba en el proceso civil, Barcelona, 1996.

RUÍZ DE LA FUENTE, C. "El principio dispositivo y las intimaciones judiciales en la prueba” en, J. Picó I Junoy (Dir.), Principios y garantías procesales: Liber Amicorum en homenaje a la profesora María Victoria Berzosa Francos, Barcelona, 2013.

SEOANE SPIEGELBERG, J. L. La prueba en la Ley de enjuiciamiento civil 1/2000, disposiciones generales y presunciones, Pamplona, 2002.

SERRA DOMÍNGUEZ, “arts. 1214 a 1253”, en, M. Albaladejo García y S. Díaz Alabart, Comentarios al Código Civil y Compilaciones forales Tomo XXVI, Vol. II, Madrid, 1991.

TARUFFO, M. La prueba de los hechos, traducción de Jordi Ferrer Beltrán, Madrid, 2011.

TÓRREZ PERALTA, W. Derecho procesal civil. Conforme al nuevo Código Procesal Civil, Managua, 2015.

VAQUERO LÓPEZ, C. "Principio de oportunidad y mediación. Alternativa viable y necesaria" Revista de Mediación, N ${ }^{\circ} 11,2012$.

VILLABELLA ARMENGOL, C. La investigación y comunicación científica en la ciencia jurídicas, Managua, 2009. 